\title{
Kinetics and Mechanism of the Pyridinolysis of $O$-Aryl Methyl Phosphonochloridothioates in Acetonitrile
}

\author{
Arun Kanti Guha, Md. Ehtesham Ul Hoque, and Hai Whang Lee* \\ Department of Chemistry, Inha University, Incheon 402-751, Korea. *E-mail: hwlee@inha.ac.kr \\ Received February 1, 2010, Accepted February 14, 2011
}

Key Words : Biphasic free energy correlation, Phosphoryl transfer reaction, Pyridinolysis, $O$-Aryl methyl phosphonochloridothioates

Continuing the experimental (anilinolyses ${ }^{1}$ and pyridinolyses $^{2}$ ) and theoretical studies ${ }^{3}$ on the phosphoryl transfer reactions, the reactions of $\mathrm{Y}-\mathrm{O}$-aryl methyl phosphonochloridothioates with X-pyridines in acetonitrile at $35.0 \pm$ $0.1{ }^{\circ} \mathrm{C}$ (Scheme 1 ) have been carried out kinetically to gain further information into the phosphoryl transfer reactions and substituent effects of the nucleophiles and substrates on the reaction mechanism, as well as to compare with the relevant pyridinolyses of $\mathrm{R}_{1} \mathrm{R}_{2} \mathrm{P}(=\mathrm{S}) \mathrm{Cl}$-type substrates in $\mathrm{MeCN}$.

The pseudo-first-order rate constants observed $\left(k_{\text {obsd }}\right)$ for all reactions obey eq. $(1)$ with negligible $k_{0}(\approx 0)$ in $\mathrm{MeCN}$. The second-order rate constants were determined with at least five pyridine concentrations $\left[\mathrm{XC}_{5} \mathrm{H}_{4} \mathrm{~N}\right]$. No third-order or higher-order terms were detected, and no complications were found in the determination of $k_{\text {obsd }}$ or in the linear plot

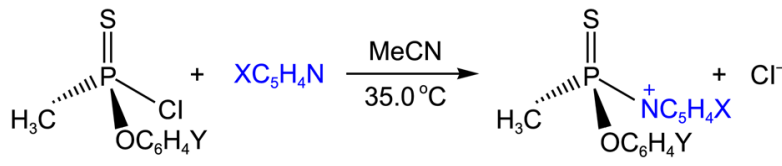

$\mathrm{X}=4-\mathrm{MeO}, 4-\mathrm{Me}, 3-\mathrm{Me}, \mathrm{H}, 3-\mathrm{Cl}, 3-\mathrm{Ac}, 4-\mathrm{Ac}$ $\mathrm{Y}=4-\mathrm{MeO}, 4-\mathrm{Me}, \mathrm{H}, 3-\mathrm{Cl}, 4-\mathrm{CN}$

Scheme 1. The studied reaction system. of eq. (1). This suggests that there is no base-catalysis or noticeable side reactions, and the overall reaction follows the path given by Scheme 1 .

$$
k_{\text {obsd }}=k_{0}+k_{2}\left[\mathrm{XC}_{5} \mathrm{H}_{4} \mathrm{~N}\right]
$$

The second-order rate constants $\left[k_{2}\left(\mathrm{M}^{-1} \mathrm{~s}^{-1}\right)\right]$ are summarized in Table 1 , together with selectivity parameters, $\rho_{\mathrm{X}}$, $\beta_{\mathrm{X}}, \rho_{\mathrm{Y}}$, and $\rho_{\mathrm{XY}}$. The $\beta_{\mathrm{X}}$ values were determined using $\mathrm{p} K_{\mathrm{a}}$ values in water; the slopes from the plots of $\log k_{2}(\mathrm{MeCN})$ against $\mathrm{p} K_{\mathrm{a}}\left(\mathrm{H}_{2} \mathrm{O}\right)$. Justification of this procedure has been experimentally and theoretically provided. ${ }^{6}$ The substituent effects in the nucleophiles and substrates on the rates are compatible with those for a typical nucleophilic substitution reaction with positive charge development at the nucleophilic $\mathrm{N}$ atom $\left(\rho_{\mathrm{X}}<0\right.$ and $\left.\beta_{\mathrm{X}}>0\right)$ and negative charge development at the reaction center $\mathrm{P}$ atom $\left(\rho_{\mathrm{Y}}>0\right)$ in the transition state (TS). However, the Hammett $\left(\log k_{2} v s \sigma_{\mathrm{X}}\right)$ and Brönsted [log $k_{2} v s$ p $\left.K_{\mathrm{a}}(\mathrm{X})\right]$ plots for substituent $\mathrm{X}$ variations in the nucleophiles exhibit a break region between $\mathrm{X}=\mathrm{H}$ and 3-Cl, resulting in discrete two parts with one part for the strongly basic pyridines $(\mathrm{X}=4-\mathrm{MeO}$, 4-Me, 3-Me, $\mathrm{H})$ and the other part for the weakly basic pyridines $(\mathrm{X}=3$ $\mathrm{Cl}, 3-\mathrm{Ac}, 4-\mathrm{Ac}$ ), respectively (Fig. 1). The Hammett plots $\left(\log k_{2} v s \sigma_{\mathrm{Y}}\right)$ for substituent $\mathrm{Y}$ variations in the substrates are biphasic downwards with a break point at $\mathrm{Y}=\mathrm{H}$ (Fig. 2).

Table 1. Second-Order Rate Constants $\left(k_{2} \times 10^{3} / \mathrm{M}^{-1} \mathrm{~s}^{-1}\right)$ and Selectivity Parameters ${ }^{a}$ of the Reactions of Y-O-Aryl Methyl Phosphonochloridothioates with X-Pyridines in $\mathrm{MeCN}$ at $35.0^{\circ} \mathrm{C}$

\begin{tabular}{cccccccc}
\hline $\mathrm{X} \backslash \mathrm{Y}$ & $4-\mathrm{MeO}$ & $4-\mathrm{Me}$ & $\mathrm{H}$ & $3-\mathrm{Cl}$ & $4-\mathrm{CN}$ & $\rho_{\mathrm{Y}}{ }^{b}$ & $\rho_{\mathrm{Y}}{ }^{c}$ \\
\hline $4-\mathrm{MeO}$ & 88.0 & 213 & 425 & 852 & 982 & $2.45 \pm 0.11$ & $0.56 \pm 0.08$ \\
$4-\mathrm{Me}$ & 16.0 & 31.2 & 62.3 & 218 & 434 & $2.14 \pm 0.06$ & $1.29 \pm 0.06$ \\
$3-\mathrm{Me}$ & 10.3 & 23.0 & 41.0 & 144 & 290 & $2.14 \pm 0.10$ & $1.30 \pm 0.06$ \\
$\mathrm{H}$ & 4.30 & 7.20 & 14.3 & 51.0 & 117 & $1.91 \pm 0.02$ & $1.39 \pm 0.03$ \\
$3-\mathrm{Cl}$ & 2.50 & 6.20 & 12.3 & 43.1 & 86.2 & $2.48 \pm 0.11$ & $1.29 \pm 0.06$ \\
$3-\mathrm{Ac}$ & 2.20 & 5.60 & 11.2 & 40.1 & 80.2 & $2.53 \pm 0.12$ & $1.30 \pm 0.06$ \\
$4-\mathrm{Ac}$ & 0.301 & 0.751 & 1.50 & 4.07 & 11.0 & $2.50 \pm 0.11$ & $1.30 \pm 0.04$ \\
$-\rho_{\mathrm{X}}{ }^{d, e}$ & $4.54 \pm 0.16$ & $4.98 \pm 0.20$ & $5.06 \pm 0.19$ & $4.20 \pm 0.13$ & $3.20 \pm 0.09$ & $\rho_{\mathrm{XY}}{ }^{b, d, j}=$ & $\rho_{\mathrm{XY}}{ }^{c, d, l}=$ \\
$\beta_{\mathrm{X}}{ }^{d, f}$ & $0.94 \pm 0.12$ & $1.03 \pm 0.15$ & $1.04 \pm 0.14$ & $0.87 \pm 0.07$ & $0.66 \pm 0.05$ & $-1.76 \pm 0.17$ & $2.80 \pm 0.13$ \\
$-\rho_{\mathrm{X}}{ }^{g, h}$ & $7.12 \pm 0.01$ & $7.14 \pm 0.02$ & $7.13 \pm 0.02$ & $8.05 \pm 0.03$ & $7.01 \pm 0.03$ & $\rho_{\mathrm{XY}}^{b, g, k}=$ & $\rho_{\mathrm{XY}}{ }^{c, g, m}=$ \\
$\beta_{\mathrm{X}}{ }^{i}$ & 2.14 & 2.13 & 2.13 & 2.38 & 2.08 & $-0.02 \pm 0.09$ & $0.07 \pm 0.05$ \\
\hline
\end{tabular}

${ }^{a}$ The $\sigma$ values were taken from ref 4 . The $\mathrm{p} K_{\mathrm{a}}$ values were taken from ref $5 .{ }^{b} \mathrm{Y}=(4-\mathrm{MeO}, 4-\mathrm{Me}, \mathrm{H})$. Correlation coefficients, $r$, are better than $0.971 .{ }^{c} \mathrm{Y}$ $=(\mathrm{H}, 3-\mathrm{Cl}, 4-\mathrm{CN}) \cdot r \geq 0.957 .{ }^{d} \mathrm{X}=(4-\mathrm{MeO}, 4-\mathrm{Me}, 3-\mathrm{Me}, \mathrm{H}) .{ }^{e} r \geq 0.962 .{ }^{f} r \geq 0.980 .{ }^{g} \mathrm{X}=(3-\mathrm{Cl}, 3-\mathrm{Ac}, 4-\mathrm{Ac}) \cdot{ }^{h} r \geq 0.999 .{ }^{i} \mathrm{Calculated}$ with $\mathrm{X}=3-\mathrm{Cl}$ and $4-$ Ac. Note that $\mathrm{X}=3$-Ac is not considered. ${ }^{j} r=0.941 .{ }^{k} r=0.983 .{ }^{l} r=0.961 .{ }^{m} r=0.996$. 

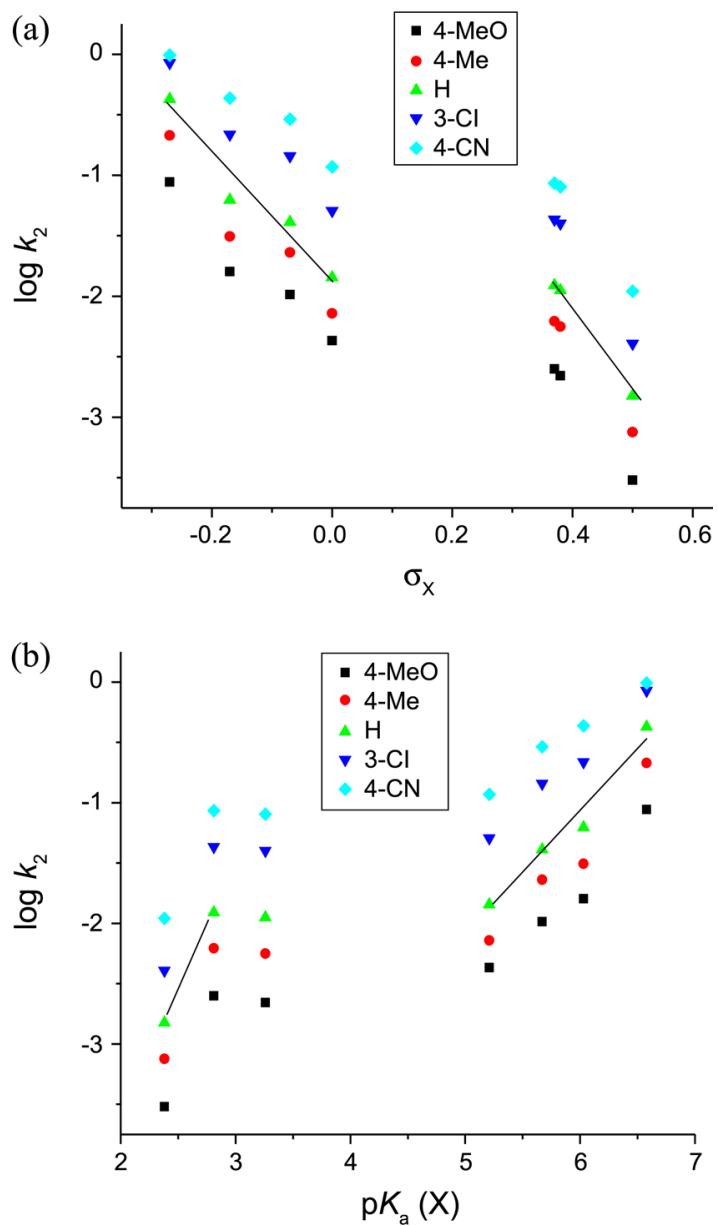

Figure 1. (a) The Hammett $\left(\log k_{2} v s \sigma_{\mathrm{X}}\right)$ and (b) Brönsted [log $k_{2}$ $v s \mathrm{p} K_{\mathrm{a}}(\mathrm{X})$ ] plots of the reactions of $\mathrm{Y}-O$-aryl methyl phosphonochloridothioates with $\mathrm{X}$-pyridines in $\mathrm{MeCN}$ at $35.0^{\circ} \mathrm{C}$.

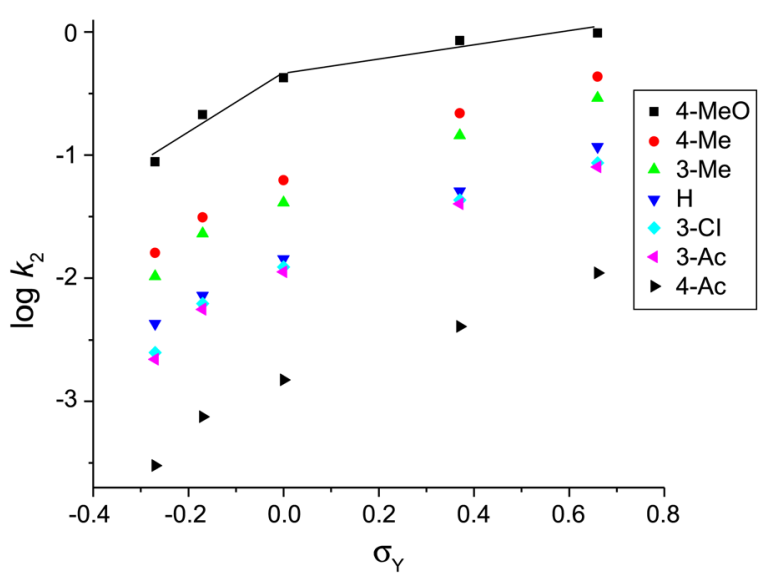

Figure 2. The Hammett plots $\left(\log k_{2} v s \sigma_{\mathrm{Y}}\right)$ of the reactions of Y-Oaryl methyl phosphonochloridothioates with X-pyridines in $\mathrm{MeCN}$ at $35.0^{\circ} \mathrm{C}$.

It should be noted that the $\beta_{\mathrm{X}}$ values for the weakly basic pyridines are calculated from the two pyridines with $\mathrm{X}=3$ $\mathrm{Cl}$ and 4-Ac, excluding $\mathrm{X}=3-\mathrm{Ac}$, since the sequence of the magnitudes of $\sigma_{\mathrm{X}}$ and $\mathrm{p} K_{\mathrm{a}}(\mathrm{X})$ values of 3-Cl, 3-Ac, and 4-Ac substituent is not consistency: $\sigma_{\mathrm{X}}=0.37(3-\mathrm{Cl})<0.38$
Ac) $<0.50(4-\mathrm{Ac})$ whereas $\mathrm{p} K_{\mathrm{a}}(\mathrm{X})=2.38(4-\mathrm{Ac})<2.81(3-$ $\mathrm{Cl})<3.26(3-\mathrm{Ac})$. The $\beta_{\mathrm{X}}$ values obtained with the two weakly basic pyridines may be more or less overestimated, however, the tendency of the substituent $\mathrm{X}$ effects with the weakly basic pyridines can be discussed by the magnitudes of $\rho_{\mathrm{X}}$ values together with the $\beta_{\mathrm{X}}$ values. The magnitudes of $\rho_{\mathrm{X}}(=-7.01$ to -8.05$)$ and $\beta_{\mathrm{X}}(=2.08-2.38)$ values with the weakly basic pyridines $(\mathrm{X}=3-\mathrm{Cl}, 3-\mathrm{Ac}, 4-\mathrm{Ac})$ are greater than those $\left(\rho_{\mathrm{X}}=-3.20\right.$ to -5.06 and $\left.\beta_{\mathrm{X}}=0.66-1.04\right)$ with the strongly basic pyridines $(\mathrm{X}=4-\mathrm{MeO}, 4-\mathrm{Me}, 3-\mathrm{Me}, \mathrm{H})$, indicating greater degree of bond formation (or greater positive charge development on the nucleophilic $\mathrm{N}$ atom) for the weakly basic pyridines than for the strongly basic pyridines. Furthermore, the magnitudes of $\rho_{\mathrm{X}}$ and $\beta_{\mathrm{X}}$ values with the weakly basic pyridines are not only great but also nearly constant $\left(\rho_{\mathrm{X}}=-7.10 \pm 0.09\right.$ and $\beta_{\mathrm{X}}=2.10 \pm 0.04$ when excluding $\mathrm{Y}=3-\mathrm{Cl}$ ) regardless of the nature of substituent $\mathrm{Y}$, electron-donating or -withdrawing (vide infra). The $\rho_{\mathrm{Y}}(=1.91$ 2.53) values for the weaker electrophiles with electrondonating substituents $\mathrm{Y}(=4-\mathrm{MeO}, 4-\mathrm{Me}, \mathrm{H})$ are somewhat greater than those $\left(\rho_{\mathrm{Y}}=0.56-1.39\right)$ for the stronger electrophiles with electron-withdrawing substituents $\mathrm{Y}(=\mathrm{H}, 3-\mathrm{Cl}$, 4-CN), indicating the greater negative charge development on the $\mathrm{P}$ reaction center for the weaker electrophiles than for the stronger electrophiles. The magnitudes of $\rho_{\mathrm{Y}}$ values with the weakly basic pyridines are almost constant for both the weaker $\left(\rho_{\mathrm{Y}}=2.50 \pm 0.03\right)$ and stronger $\left(\rho_{\mathrm{Y}}=1.30 \pm 0.01\right)$ elctrophiles (vide infra).

The cross-interaction constants (CICs; $\left.\rho_{\mathrm{XY}}\right)$, eqs. (2), are determined, where $\mathrm{X}$ and $\mathrm{Y}$ represent the substituents in the nucleophile and substrate, respectively. ${ }^{7}$ The sign and magnitude of the CICs have made it possible to correctly interpret the reaction mechanism and degree of tightness of the TS, respectively. In general, the $\rho_{\mathrm{XY}}$ has a negative value in a stepwise mechanism with a rate-limiting bond formation and a concerted $S_{N} 2$. In contrast, it has a positive value for a stepwise mechanism with a rate-limiting leaving group expulsion from the intermediate. The magnitude of $\rho_{\mathrm{XY}}$ is inversely proportional to the distance between $\mathrm{X}$ and $\mathrm{Y}$ through the reaction center. ${ }^{7}$

$$
\begin{gathered}
\log \left(k_{\mathrm{XY}} / k_{\mathrm{HH}}\right)=\rho_{\mathrm{X}} \sigma_{\mathrm{X}}+\rho_{\mathrm{Y}} \sigma_{\mathrm{Y}}+\rho_{\mathrm{XY}} \sigma_{\mathrm{X}} \sigma_{\mathrm{Y}} \\
\rho_{\mathrm{XY}}=\rho_{\mathrm{X}} / \sigma_{\mathrm{Y}}=\rho_{\mathrm{Y}} / \sigma_{\mathrm{X}}
\end{gathered}
$$

Since both Hammett plots for substituent $\mathrm{X}$ and $\mathrm{Y}$ variations are biphasic with a break region and point, respectively, four values of $\rho_{\mathrm{XY}}$ can be obtained by dividing into four blocks: $(a) \rho_{\mathrm{XY}}=-1.76(r=0.941)$ for the stronger nucleophiles and weaker electrophiles $(\mathrm{X}=4-\mathrm{MeO}$, 4-Me, 3-Me, H and $\mathrm{Y}=4-\mathrm{MeO}, 4-\mathrm{Me}, \mathrm{H}) ;(b) \rho_{\mathrm{XY}}=-0.02(r=0.983)$ for the weaker nucleophiles and electrophiles $(\mathrm{X}=3-\mathrm{Cl}, 3-\mathrm{Ac}$, 4-Ac and $\mathrm{Y}=4-\mathrm{MeO}, 4-\mathrm{Me}, \mathrm{H})$; $(c) \rho_{\mathrm{XY}}=+2.80(r=0.961)$ for the stronger nucleophiles and electrophiles $(\mathrm{X}=4-\mathrm{MeO}$, 4-Me, 3-Me, $\mathrm{H}$ and $\mathrm{Y}=\mathrm{H}, 3-\mathrm{Cl}, 4-\mathrm{CN})$; (d) $\rho_{\mathrm{XY}}=+0.07(r=$ $0.996)$ for the weaker nucleophiles and stronger electrophiles $(\mathrm{X}=3-\mathrm{Cl}, 3-\mathrm{Ac}, 4-\mathrm{Ac}$ and $\mathrm{Y}=\mathrm{H}, 3-\mathrm{Cl}, 4-\mathrm{CN})$. However, the $\rho_{\mathrm{XY}}$ values have some problems with credibility because of: (i) the $\rho_{\mathrm{XY}}$ values are calculated with twelve 
second-order rate constants for $a$ and $c$ blocks, and with nine for $b$ and $d$ blocks; ${ }^{8}$ (ii) the correlation coefficients, $r(\leq 0.98)$, for $a, b$, and $c$ blocks are not tolerable; (iii) moreover, the constancy of $\rho_{\mathrm{X}}$ and $\rho_{\mathrm{Y}}$ values with the weakly basic pyridines (vide supra) leads to unacceptable sign of $\rho_{\mathrm{XY}}$ values for $b$ and $d$ blocks (despite $r=0.996$ for $d$ block). Consequently, the signs of $\rho_{\mathrm{XY}}$ for $a$ and $c$ blocks can be acceptable while those for $b$ and $d$ blocks cannot be acceptable to discuss the reaction mechanism. In other words, the magnitude of $\rho_{\mathrm{XY}}$ is null for the weakly basic pyridines, $b$ and $d$ blocks.

The null of $\rho_{\mathrm{XY}}$ value suggests the absence of the crossinteraction between $\mathrm{X}$ and $\mathrm{Y}$. This phenomenon can be occurred: (i) X and Y are too far apart to interact; (ii) the distance between $\mathrm{X}$ and $\mathrm{Y}$ does not vary. Thus, the null of $\rho_{\mathrm{XY}}$ value indicates a special stepwise mechanism with a rate-limiting bond breaking where the distance between $\mathrm{X}$ and $\mathrm{Y}$ does not vary from the intermediate to the second TS. It is worth noting that the magnitudes of $\rho_{\mathrm{X}}$ and $\beta_{\mathrm{X}}$ values involving a frontside attack TSf are greater than those involving a backside attack TSb (Scheme 2). ${ }^{2 \mathrm{c}}$

The authors propose mechanism for the studied reaction system, divided into four blocks, as follows: $(a)$ a stepwise mechanism with a rate-limiting bond formation based on the negative sign of $\rho_{\mathrm{XY}}$ and a backside attack TSb (Scheme 2) based on the relatively small magnitudes of $\rho_{\mathrm{X}}$ and $\beta_{\mathrm{X}} ;(b)$ a stepwise mechanism with a rate-limiting leaving group departure from the intermediate based on the null of $\rho_{\mathrm{XY}}$ value and a frontside attack TSf (Scheme 2) based on the considerably great magnitudes of $\rho_{\mathrm{X}}$ and $\beta_{\mathrm{X}}$ values; (c) a stepwise mechanism with a rate-limiting leaving group departure from the intermediate based on the positive sign of $\rho_{\mathrm{XY}}$, and a backside attack TSb on the basis of relatively small magnitudes of $\rho_{\mathrm{x}}$ and $\beta_{\mathrm{x}}$ values; $(d)$ a stepwise mechanism with a rate-limiting leaving group departure from the intermediate based on the null of $\rho_{\mathrm{XY}}$ value and a frontside attack TSf on the basis of the considerably great magnitude of $\rho_{\mathrm{X}}$ and $\beta_{\mathrm{X}}$ values. The greater magnitudes of $\rho_{\mathrm{Y}}$ values with the weaker electrophiles ( $a$ and $b$ blocks) indicate the smaller degree of bond breaking, suggesting the tighter TS with the weaker electrophiles than with the stronger electrophiles ( $c$ and $d$ blocks).

In the present work, the unusual results should be stressed
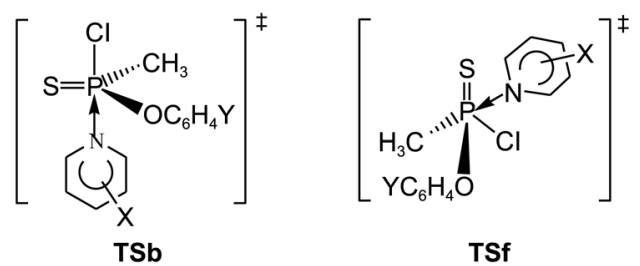

Scheme 2. Backside attack TSb and frontside attack TSf.

regarding the magnitudes of the $\rho_{\mathrm{X}}, \beta_{\mathrm{X}}$, and $\rho_{\mathrm{XY}}$ values with the weakly basic pyridines: (i) the studied system is the only one having significantly greater magnitudes of the $\rho_{\mathrm{X}}$ and $\beta_{\mathrm{X}}$ values compared to with the strongly basic pyridines (Table 2); (ii) the studied system is the only one having the null of $\rho_{\mathrm{XY}}$ values for both the stronger and weaker electrophiles (Table 2): (iii) the null of $\rho_{\mathrm{XY}}$ value implies that the distance between $\mathrm{X}$ and $\mathrm{Y}$ for any kind of substituents $\mathrm{X}$ and $\mathrm{Y}$ is invariable in the TS. (iv) the null of $\rho_{\mathrm{XY}}$ value with the whole spectrum from electron-donating to -withdrawing Y substituents is observed for the first time.

Table 2 shows the second-order rate constants with unsubstituted pyridine at $35.0^{\circ} \mathrm{C}$ and selectivity parameters ( $\beta_{\mathrm{X}}$ and $\rho_{\mathrm{XY}}$ ) for the pyridinolyses of $\mathrm{R}_{1} \mathrm{R}_{2} \mathrm{P}(=\mathrm{S})$ Cl-type substrates in $\mathrm{MeCN}$. The sequence of the row is the order of the second-order rate constant. In Table 2, only the pyridinolyses of Y-O-aryl phenyl phosphonochloridothioates (2) exhibit linear free energy correlation for both substituent $\mathrm{X}$ and $\mathrm{Y}$ variations. In contrast to the present work (1), the biphasic concave upward free energy correlations for substituent $\mathrm{X}$ variations for 3-7 were rationalized by the attacking direction change from a frontside with the strongly basic pyridines to a backside with the weakly basic pyridines. The difference between $1\left[\left(\mathrm{YC}_{6} \mathrm{H}_{4} \mathrm{O}\right) \mathrm{MeP}(=\mathrm{S}) \mathrm{Cl}\right]$ and $2\left[\left(\mathrm{YC}_{6} \mathrm{H}_{4} \mathrm{O}\right) \mathrm{PhP}(=\mathrm{S}) \mathrm{Cl}\right]$ is one ligand, $\mathrm{Ph}$ or $\mathrm{Me}$, However, the anilinolysis of $\mathbf{1}$ showed biphasic concave downward Hammett and Brönsted plots with a break region, ${ }^{1 \mathrm{k}}$ which is the only one showing nonlinear free energy correlations among nineteen $\mathrm{R}_{1} \mathrm{R}_{2} \mathrm{P}(=\mathrm{O}$ or $\mathrm{S}) \mathrm{Cl}$-type substrates. ${ }^{1 \mathrm{a}-\mathrm{l}}$ Furthermore, the deuterium kinetic isotope effects (DKIEs) of 1 involving deuterated anilines $\left(\mathrm{XC}_{6} \mathrm{H}_{4} \mathrm{ND}_{2}\right)$ showed different trends compared to other $\mathrm{R}_{1} \mathrm{R}_{2} \mathrm{P}(=\mathrm{O}$ or $\mathrm{S})$ Cl-type substrates; primary normal DKIEs $\left(k_{\mathrm{H}} / k_{\mathrm{D}}=1.03-1.30\right)$ with the strongly basic anilines and extremely large secondary

Table 2. Summary of the Second-Order Rate Constants $\left(k_{2} \times 10^{3} / \mathrm{M}^{-1} \mathrm{~s}^{-1}\right)$ at $35.0^{\circ} \mathrm{C}$ and Selectivity Parameters for the Reactions of $\mathrm{R}_{1} \mathrm{R}_{2} \mathrm{P}(=\mathrm{S}) \mathrm{Cl}$-type Substrates with X-pyridines in $\mathrm{MeCN}$

\begin{tabular}{ccccccc}
\hline nо & $\mathrm{R}_{1}$ & $\mathrm{R}_{2}$ & $k_{2} \times 10^{3 a}$ & $\beta_{\mathrm{X}}$ & $\rho_{\mathrm{XY}}$ & ref. \\
\hline $\mathbf{1}$ & $\mathrm{Me}$ & $\mathrm{YC}_{6} \mathrm{H}_{4} \mathrm{O}$ & $14.3^{b}$ & $0.66-1.04 / 2.08-2.38^{d}$ & $-1.76 / 0 / 2.80 / 0^{e}$ & this work \\
$\mathbf{2}$ & $\mathrm{Ph}$ & $\mathrm{YC}_{6} \mathrm{H}_{4} \mathrm{O}$ & $11.2^{b}$ & $0.87-0.95$ & -0.46 & $2 \mathrm{f}$ \\
$\mathbf{3}$ & $\mathrm{Ph}$ & $\mathrm{Ph}$ & 1.83 & $1.53 / 0.38^{d}$ & - & $2 \mathrm{~d}$ \\
$\mathbf{4}$ & $\mathrm{MeO}$ & $\mathrm{MeO}$ & $1.54^{c}$ & $1.09 / 0.20^{d}$ & - & $2 \mathrm{~g}$ \\
$\mathbf{5}$ & $\mathrm{EtO}$ & $\mathrm{EtO}$ & $1.19^{c}$ & $1.02 / 0.29^{d}$ & - & $2 \mathrm{~g}$ \\
$\mathbf{6}$ & $\mathrm{Me}$ & $\mathrm{Me}$ & 0.744 & $0.97 / 0.27^{d}$ & - & $2 \mathrm{~h}$ \\
$\mathbf{7}$ & $\mathrm{PhO}$ & $\mathrm{YC}_{6} \mathrm{H}_{4} \mathrm{O}$ & $0.333^{b}$ & $1.36-1.50 / 0.23-0.48^{c}$ & $2.42 / 5.14 /-1.02 /-0.04^{f}$ & $2 \mathrm{k}$ \\
\hline
\end{tabular}

${ }^{a}$ For the reactions with unsubstituted pyridine $(\mathrm{X}=\mathrm{H})$ at $35.0{ }^{\circ} \mathrm{C} .{ }^{b}$ For the reactions of unsubstituted substrate $(\mathrm{Y}=\mathrm{H}) .{ }^{c}$ Extrapolated values from the Arrhenius plots. ${ }^{d}$ For more/less basic pyridines. ${ }^{e}$ See the footnote in Table $1 .{ }^{f}$ The same sequence of substituent X and Y as footnote $d$. 
inverse DKIEs $\left[k_{\mathrm{H}} / k_{\mathrm{D}}=0.367\right.$ (unprecedented smallest value)$0.567]$ with the weakly basic anilines. ${ }^{1 \mathrm{k}}$ A subtle combination of small $(\mathrm{Me})$ and large $\left(\mathrm{YC}_{6} \mathrm{H}_{4} \mathrm{O}\right)$ ligands in $\mathbf{1}$ leads to an unexpected results for the pyridinolysis and anilinolysis.

In summary, the reactions of Y-O-aryl methyl phosphonochloridothioates with X-pyridines are studied kinetically in $\mathrm{MeCN}$ at $35.0{ }^{\circ} \mathrm{C}$. The Hammett and Brönsted plots for substituent $\mathrm{X}$ variations in the nucleophiles are biphasic with a break region between $\mathrm{X}=\mathrm{H}$ and 3-Cl, while the Hammett plots for substituent $\mathrm{Y}$ variations in the substrates are biphasic concave downwards with a break point at $\mathrm{Y}=\mathrm{H}$. The stepwise mechanism is proposed on the basis of the $\rho_{\mathrm{X}}$, $\beta_{\mathrm{X}}$, and $\rho_{\mathrm{XY}}$ values as follows: a rate-limiting bond formation involving a backside attack for the stronger nucleophiles and weaker electrophiles; a rate-limiting bond breaking involving a frontside attack for the weaker nucleophiles and electrophiles with the null of $\rho_{\mathrm{XY}}$ value; a rate-limiting bond breaking involving a backside attack for the stronger nucleophiles and electrophiles; a rate-limiting bond breaking involving a frontside attack for the weaker nucleophiles and stronger electrophiles with the null of $\rho_{\mathrm{XY}}$ value. A combination of small $(\mathrm{Me})$ and large $\left(\mathrm{YC}_{6} \mathrm{H}_{4} \mathrm{O}\right)$ ligands leads to an unexpected results.

\section{Experimental Section}

Materials. Y-O-Aryl methyl phosphonochloridothioates were prepared as described previously. ${ }^{1 \mathrm{k}}$ GR grade pyridines were used without further purification and all other materials were as reported previously. ${ }^{1 \mathrm{k}, 2}$

Kinetic Procedure. Rates were measured conductometrically at $35.0{ }^{\circ} \mathrm{C}$. The conductivity bridge used in this work was a self-made computer automated A/D converter conductivity bridge. Pseudo-first-order rate constants, $k_{\text {obsd }}$ were measured by curve fitting analysis in origin program with a large excess of pyridines, [Substrates] $=1 \times 10^{-3} \mathrm{M}$ and $[\mathrm{X}$ Pyridine $]=0.05-0.13 \mathrm{M}$. Second-order rate constants, $k_{2}$, were obtained from the slope of a plot of $k_{\text {obsd }} v s$. [XPyridine] with at least five concentrations of pyridine. The $k_{2}$ values are the averages of more than three runs.

Product Analysis. Phenyl methyl phosphonochloridothioate was reacted with excess 4-acetylepyridine for more than 15 half-lives at $35.0{ }^{\circ} \mathrm{C}$ in acetonitrile. Acetonitrile was evaporated under reduced pressure and ether was added. The product was isolated as ether insoluble fraction. The product was purified to remove excess pyridine by washing several times with acetonitrile and ether. Analytical data of the product were as follows:

$\left(\mathrm{C}_{6} \mathrm{H}_{5} \mathrm{O}\right)\left(\mathrm{CH}_{3}\right) \mathbf{P}(=\mathrm{S}) \mathbf{N}^{+} \mathrm{C}_{5} \mathrm{H}_{4}-4-\mathrm{COCH}_{3} \mathrm{Cl}^{-}$. Gummy-solid; IR (neat) 3073 (C-H, aromatic), 1639, $1542\left(\mathrm{P}-\mathrm{O}-\mathrm{C}_{6} \mathrm{H}_{4}\right)$, $1255\left(\mathrm{P}-\mathrm{CH}_{3}\right), 753(\mathrm{P}=\mathrm{S}) ;{ }^{1} \mathrm{H}$ NMR $\left(400 \mathrm{MHz}, \mathrm{CDCl}_{3}\right) \delta$ $9.15(\mathrm{~d}, J=8.4 \mathrm{~Hz}, 2 \mathrm{H}$, pyridinium $), \delta 8.76(\mathrm{~d}, J=8.4 \mathrm{~Hz}$, $2 \mathrm{H}$, pyridinium), 8.23-8.26 (d, $J=8.4 \mathrm{~Hz}, 2 \mathrm{H}$, phenyl), 7.41$7.46(\mathrm{~d}, J=6.8 \mathrm{~Hz}, 2 \mathrm{H}$, phenyl), $7.10(\mathrm{t}, J=8.4 \mathrm{~Hz}, 1 \mathrm{H}$, phenyl), $2.62\left(\mathrm{~s}, 6 \mathrm{H}, \mathrm{P}-\mathrm{CH}_{3}-\mathrm{H}, \mathrm{COCH}_{3}-\mathrm{H}\right) ;{ }^{13} \mathrm{C}$ NMR $(100$ $\left.\mathrm{MHz}, \mathrm{CDCl}_{3}\right) \delta 196.42\left(\mathrm{COCH}_{3}\right), 153.01,149.50,135.80$, $132.38,129.99,129.69,123.76,121.69(\mathrm{C}=\mathrm{C}$, aromatic $)$,
$26.67\left(\mathrm{COCH}_{3}\right), 20.69\left(\mathrm{P}-\mathrm{CH}_{3}\right) ;{ }^{31} \mathrm{P}$ NMR $\left(162 \mathrm{MHz}, \mathrm{CDCl}_{3}\right)$ $\delta 91.07$ (s, 1P, $\mathrm{P}=\mathrm{S}$ ); Anal. Calcd. for $\mathrm{C}_{14} \mathrm{H}_{15} \mathrm{NO}_{2} \mathrm{PSCl}$ : $\mathrm{C}$, 51.30; H, 4.61; N, 4.27. Found: C, 51.92; H, 4.38; N, 4.60.

Acknowledgments. This work was supported by the Brain Korea 21 Program from National Research Foundation of Korea.

\section{References and Notes}

1. (a) Guha, A. K.; Lee, H. W.; Lee, I. J. Chem. Soc., Perkin Trans. 2 1999, 765. (b) Lee, H. W.; Guha, A. K.; Lee, I. Int. J. Chem. Kinet. 2002, 34, 632. (c) Hoque, M. E. U.; Dey, S.; Guha, A. K.; Kim, C. K.; Lee, B. S.; Lee, H. W. J. Org. Chem. 2007, 72, 5493. (d) Hoque, M. E. U.; Lee, H. W. Bull. Korean Chem. Soc. 2007, 28, 936. (e) Dey, N. K.; Han, I. S.; Lee, H. W. Bull. Korean Chem. Soc. 2007, 28, 2003. (f) Hoque, M. E. U.; Dey, N. K.; Kim, C. K.; Lee, B. S.; Lee, H. W. Org. Biomol. Chem. 2007, 5, 3944. (g) Dey, N. K.; Hoque, M. E. U.; Kim, C. K.; Lee, B. S.; Lee, H. W. J. Phys. Org. Chem. 2008, 21, 544. (h) Lumbiny, B. J.; Lee, H. W. Bull. Korean Chem. Soc. 2008, 29, 2065. (i) Dey, N. K.; Hoque, M. E. U.; Kim, C. K.; Lee, B. S.; Lee, H. W. J. Phys. Org. Chem. 2009, 22, 425. (j) Dey, N. K.; Kim, C. K.; Lee, H. W. Bull. Korean Chem. Soc. 2009, 30, 975. (k) Hoque, M. E. U.; Guha, A. K.; Kim, C. K.; Lee, B. S.; Lee, H. W. Org. Biomol. Chem. 2009, 7, 2919. (l) Dey, N. K.; Lee, H. W. Bull. Korean Chem. Soc. 2010, 31, 1403. (m) Dey, N. K.; Kim, C. K.; Lee, H. W. Org. Biomol. Chem. 2011, 9, 717.

2. (a) Guha, A. K.; Lee, H. W.; Lee, I. J. Org. Chem. 2000, 65, 12. (b) Lee, H. W.; Guha, A. K.; Kim, C. K.; Lee, I. J. Org. Chem. 2002, 67, 2215. (c) Adhikary, K. K.; Lee, H. W.; Lee, I. Bull. Korean Chem. Soc. 2003, 24, 1135. (d) Hoque, M. E. U.; Dey, N. K.; Guha, A. K.; Kim, C. K.; Lee, B. S.; Lee, H. W. Bull. Korean Chem. Soc. 2007, 28, 1797. (e) Adhikary, K. K.; Lumbiny, B. J.; Kim, C. K.; Lee, H. W. Bull. Korean Chem. Soc. 2008, 29, 851. (f) Lumbiny, B. J.; Adhikary, K. K.; Lee, B. S.; Lee, H. W. Bull. Korean Chem. Soc. 2008, 29, 1769. (g) Dey, N. K.; Hoque, M. E. U.; Kim, C. K.; Lee, H. W. J. Phys. Org. Chem. 2010, 23, 1022. (h) Dey, N. K.; Adhikary, K. K.; Kim, C. K.; Lee, H. W. Bull. Korean Chem. Soc. 2010, 31, 3856. (i) Guha, A. K.; Kim, C. K.; Lee, H. W. J. Phys. Org. Chem. DOI.10.1002/poc.1788. (j) Dey, N. K.; Kim, C. K.; Lee, H. W. Bull. Korean Chem. Soc. 2011, 32, 709. (k) Hoque, M. E. U.; Dey, S.; Kim, C. K.; Lee, H. W. Bull. Korean Chem. Soc. 2011, 32, 1138.

3. (a) Lee, I.; Kim, C. K.; Li, H. G.; Sohn, C. K.; Kim, C. K.; Lee, H. W.; Lee, B. S. J. Am. Chem. Soc. 2000, 122, 11162. (b) Han, I. S.; Kim, C. K.; Lee, H. W. Bull. Korean Chem. Soc. 2011, 32, 889.

4. Hansch, C.; Leo, A.; Taft, R. W. Chem. Rev. 1991, 91, 165.

5. (a) Fischer, A.; Galloway, W. J.; Vaughan, J. J. Chem. Soc. 1964, 3591. (b) Dean, J. A. Handbook of Organic Chemistry; McGrawHill: New York, 1987; Chapter 8. (c) Albert, A.; Serjeant, E. P. The Determination of Ionization Constants, 3rd ed.; Chapman and Hall: New York, 1984; p 154. (d) Koh, H. J.; Han, K. L.; Lee, I. J. Org. Chem. 1999, 64, 4783. (e) Koh, H. J.; Han, K. L.; Lee, H. W.; Lee, I. J. Org. Chem. 1998, 63, 9834. The $\mathrm{p} K_{\mathrm{a}}\left(\mathrm{H}_{2} \mathrm{O}\right)$ of X-pyridines used are as follows: $\mathrm{p} K_{\mathrm{a}}\left(\mathrm{H}_{2} \mathrm{O}\right)=6.58(\mathrm{X}=4-\mathrm{MeO}) ; 6.03(4-$ $\mathrm{Me}) ; 5.67$ (3-Me); 5.21 (H); 2.81 (3-Cl); 3.26 (3-Ac); 2.38 (4-Ac).

6. (a) Lee, I.; Kim, C. K.; Han, I. S.; Lee, H. W.; Kim, W. K.; Kim, Y. B. J. Phys. Chem. B 1999, 103, 7302. (b) Coetzee, J. F. Prog. Phys. Org. Chem. 1967, 4, 45.

7. (a) Lee, I. Chem. Soc. Rev. 1990, 19, 317. (b) Lee, I. Adv. Phys. Org. Chem. 1992, 27, 57. (c) Lee, I.; Lee, H. W. Collect. Czech. Chem. Commun. 1999, 64, 1529.

8. In general, more than twenty rate constants are employed to calculate the CIC in order to minimize the experimental error. In the present work, the experimental error of the CIC is great since the sequence of the magnitudes of $\rho_{\mathrm{X}}$ and $\rho_{\mathrm{Y}}$ values for substituent $\mathrm{X}$ and $\mathrm{Y}$ variations do not show systematic consistency. 